ISSN: 0213-3563

https://doi.org/10.14201/azafea202123107134

\title{
PROTECCIÓN DE SENTIMIENTOS RELIGIOSOS Y DISCURSO DE ODIO ${ }^{1 *}$
}

\section{Protection of Religious Feelings and Hate Speech}

Rafael AlcÁCER GUIRAO

Universidad Rey Juan Carlos

Recibido: 25 de mayo de 2021

Aceptado: 9 de agosto de 2021

\section{RESUMEN}

El objetivo del trabajo es analizar el contenido y la legitimidad del delito de escarnio a los sujetos religiosos. Para ello, analizo en primer lugar cuál es el interés protegido y su fundamento de protección por vía penal. Junto a ello, se estudian también las diferencias entre el fenómeno del discurso del odio y el ámbito de aplicación del artículo 510 del Código Penal. Finalmente, también se analizan las tensiones que presenta el delito de escarnio con el ejercicio de la libertad de expresión.

Palabras clave: sentimientos religiosos; ofensas; libertad de expresión; discurso de odio.

\section{ABSTRACT}

The purpose of the work is to analyze the content and legitimacy of the crime of derision to religious feelings. To this end, I analyze in the first place which is the protected interest and its merit of protection by criminal means. Along with this, the differences with the phenomenon of hate speech and the scope of application of article 510 of the Penal Code are also studied. Finally, I also analyze the tensions that the crime of derision presents with the exercise of freedom of expression.

Key words: religious feelings; offenses; freedom of speech; hate speech.

1. *El presente trabajo se enmarca en el Proyecto de investigación "La Libertad de expresión desde la teoría del delito (DER 2017-85334-P), de los que son CoIPs Joan Josep Queralt y Sergi Cardenal, de la Universidad de Barcelona. 
1. LA PROTECCIÓN DE LOS SENTIMIENTOS RELIGIOSOS COMO SÍNTOMA DE LA DERIVA RESTRICTIVA DE LA LIBERTAD DE EXPRESIÓN

En tiempos recientes, la hiperactividad de determinadas asociaciones ultrarreligiosas, acompañada a veces por la propia Fiscalía, ha dado lugar a un inusitado incremento de querellas y denuncias por delito de escarnio a los sentimientos religiosos ${ }^{2}$. Casos como el procesamiento y absolución de Javier Krahe ${ }^{3}$ o de Willy Toledo ${ }^{4}$, la absolución (en Sevilla) ${ }^{5}$ y condena (en Málaga $)^{6}$ de las integrantes de la procesión del coño insumiso, o la incoación de un procedimiento penal contra el artista Abel Azcona ${ }^{7}$, han generado un necesario debate sobre los límites de la libertad de expresión y la legitimidad de castigar las ofensas a símbolos o instituciones como la bandera, la Corona o las religiones. Más allá del debate teórico, la exacerbada susceptibilidad e intransigencia de determinadas comunidades religiosas frente a discursos hostiles u ofensivos hacia sus prácticas y tradiciones, ha dado lugar a intensas controversias de carácter internacional, en ocasiones con trágicas consecuencias. Baste citar la fatwa a Salman Rushdie, la publicación de las caricaturas de Mahoma en el periódico danés Jyllands Posten o el caso Charlie Hebdo.

El citado incremento de procedimientos penales por delitos de expresión forma parte, a mi entender, de una creciente tendencia restrictiva sobre la libertad de expresión. Quizá sea aún pronto para determinar si es un fenómeno coyuntural o si estamos asistiendo a un cambio de modelo, en el que la deliberación pública no es ya entendida como el medio ambiente de la democracia sino únicamente como foco de conflicto y desencuentro; aunque

2. Artículo 525 del Código Penal (CP):

"1. Incurrirán en la pena de multa de ocho a doce meses los que, para ofender los sentimientos de los miembros de una confesión religiosa, hagan públicamente, de palabra, por escrito o mediante cualquier tipo de documento, escarnio de sus dogmas, creencias, ritos o ceremonias, o vejen, también públicamente, a quienes los profesan o practican.

2. En las mismas penas incurrirán los que hagan públicamente escarnio, de palabra o por escrito, de quienes no profesan religión o creencia alguna".

3. Sentencia del Juzgado de lo Penal de Madrid 235/2012, de 8 de junio, y sentencia confirmatoria de la audiencia Provincial de Madrid 224/2013, de 2 de abril.

4. Sentencia del Juzgado de lo Penal de Madrid 20/2020, de 21 de febrero, confirmada por sentencia de la audiencia Provincial de Madrid 452/2020, de 5 de noviembre.

5. Sentencia del Juzgado de lo Penal de Sevilla, 448/2019, de 9 de octubre, confirmada por la sentencia de la Audiencia Provincial de Sevilla.

6. Sentencia del Juzgado de lo Penal de Málaga 214/2020, de 10 de noviembre.

7. Auto de archivo del Juzgado de Instrucción de Pamplona 429/2016, de 10 de noviembre. 
lo cierto es que todo apunta al segundo y más pesimista diagnóstico. Parece, en efecto, que antes que como agente partícipe de la res publica, el ciudadano se asume cada vez más como víctima del discurso, como paciente vulnerable e hipersensible a las ofensas, que demanda espacios sin discurso donde sentirse seguro, y que espera que el Estado le proteja frente a quienes no piensan como ellos 8 .

Pese a la menor entidad de la sanción - comparada con otros delitos como el de incitación al odio (art. $510 \mathrm{CP}$ ) o el enaltecimiento del terrorismo (art. $578 \mathrm{CP}$ ) -, el delito de escarnio de los sentimientos religiosos encarna con particular nitidez algunas razones de ese posible cambio de modelo. El fenómeno es poliédrico y se resiste a un diagnóstico simple. Pero sí pueden enunciarse algunas de esas causas. Entre ellas, me interesa destacar la relevancia axiológica que se viene asignando a los sentimientos subjetivos, y la consiguiente atribución de ilicitud de las ofensas. En dicho clima de conformidad y de corrección política, los sentimientos subjetivos se erigen en interés personal merecedor de protección y en exclusiva medida de la ofensa sufrida, por lo que toda afectación a tales sentimientos se equipara axiológicamente al daño a un bien jurídico. Surge con ello un nuevo "derecho": el derecho a no sentirse ofendido ${ }^{10}$. Con ello la tradicional concepción liberal de la libre expresión queda cercenada en su base: el derecho a ofender, como condición necesaria para garantizar un debate desinhibido sobre asuntos públicos, se transmuta en el deber de no ofender, que a su vez se concreta en la obligación de moderar la forma y el fondo del discurso.

La inclusión de los sentimientos subjetivos bajo la esfera de lo jurídicamente protegido - y que tiene su plasmación legal en el delito de escarnio o en otros como el delito de ultrajes a los símbolos patrios (art. $543 \mathrm{CP}$ )genera el riesgo de restringir el propio contenido protegido del derecho a la libre expresión. Ello se debe a la falaz identificación que a veces se establece entre los sentimientos de ofensa y el contenido de derechos fundamentales que, como la dignidad, la igualdad o la libertad religiosa, se sitúan en conflicto con la libertad de expresión.

Esa identificación se refleja con particular claridad en otra de las causas que explican el declive de la libre expresión: las demandas de protección de

8. Al respecto, véase Hume, 2015, pp. 5 ss., y passim. En este sentido, Fox, 2016, pp. 57 ss., habla de la Snowflake generation.

9. Sobre ello, remito a Alcácer Guirao, 2019, pp. 1 ss.

10. Hume, 2015, pp. 3-4. 
la identidad cultural. Las reivindicaciones del ámbito del multiculturalismo sobre el respeto a las diferencias y particularismos de determinados grupos culturales han erigido un férreo dique a la fluidez del discurso político, al considerar lesivo de la dignidad de sus miembros toda manifestación de rechazo o menosprecio de las características, tradiciones o símbolos que conforman y cohesionan la identidad del grupo. Esas "políticas de la identidad" demandarán importantes restricciones a la libertad de expresión, pues desde la óptica de los grupos identitarios toda ofensa a las tradiciones, símbolos o características que determinan la identidad del colectivo será entendida como un ataque a la dignidad de los miembros del grupo, de igual modo que todo discurso crítico con esas tradiciones será calificado como discurso de odio, racista o discriminatorio ${ }^{11}$. Así lo han entendido autores como Jeremy Waldron, quien pese a defender la restricción penal del discurso del odio, se ha mostrado muy crítico con las reivindicaciones identitarias en este ámbito: "las políticas de la identidad - afirma este autor- contribuyen decisivamente a enturbiar las aguas del debate sobre el discurso del odio"12, por cuanto aspiran a transmutar en derechos -derivados de la dignidad y el libre desarrollo de la personalidad-pretensiones de respeto a símbolos, creencias y valores particulares, a instaurar un "derecho" a no ser ofendido y a que sean suprimidas coactivamente las opiniones ofensivas sobre los referentes identitarios ${ }^{13}$.

\section{2. ¿QUÉ PROTEGE EL DELITO DE ESCARNIO?}

\section{1. ¿Protección de la libertad religiosa?}

La legitimidad del uso del ius punendi resultará indudable si el objeto protegido se conecta con el ejercicio de un derecho fundamental. Quizás por ello, algunas voces han querido vincular las conductas de escarnio y profanación con la libertad religiosa, considerando que es una de las manifestaciones de su ejercicio la que queda menoscabada por tales conductas; de igual modo que otras lo han vinculado al derecho al honor o a la dignidad del colectivo de pertenencia. Con ello no solo se justificaría prima facie el recurso a la san-

11. En este sentido, denuncia Fox, 2016, p. 26, el modo en que el multiculturalismo ha usurpado el antirracismo. Véase también Hume, 2015, p. 65-66, sobre los efectos de esas políticas de la identidad sobre la libertad de expresión.

12. Waldron, 2012, p. 136.

13. Waldron, 2012, pp. 131 ss. 
ción penal - dado el estatus constitucional del bien protegido-, sino que se quedarían equilibrados los platos de la balanza: el conflicto se planteará entre derechos, entre libertad (de expresión) y libertad (religiosa) ${ }^{14}$.

La vinculación de los sentimientos subjetivos de los creyentes con la libertad religiosa se ha intentado establecer por diferentes vías. Por algunos autores, se derivaría de la vertiente interna del derecho fundamental. Esa dimensión interna protege la existencia de las íntimas convicciones y creencias religiosas, filosóficas o ideológicas de las personas, un espacio de autodeterminación intelectual ante el fenómeno religioso o ideológico, vinculado a la propia personalidad y dignidad individual. En quienes profesan una religión, se afirma, tales creencias generan sentimientos y emociones intensas, porque "la adhesión a unas creencias religiosas, o a una ideología, a la vez que conforma la personalidad del individuo y genera inevitablemente una comunión sentimental con las mismas". Por ello, las ofensas o el desprecio a los referentes de esas creencias menoscabarían los vínculos de esa adhesión y, con ello, la dimensión interna de la libertad religiosa ${ }^{15}$.

Desde otra perspectiva, se ha afirmado que la libertad religiosa comprende no solo la libertad para ejercer libremente una religión - dimensión externa - y para no ser forzado a asumir o comunicar sus creencias - dimensión interna-, sino también la posibilidad de goce y pacífico disfrute de la práctica religiosa, sin interferencias que alteren el vínculo con los símbolos y $\operatorname{credos}^{16}$. A partir de esa premisa, se concluye que los sentimientos religiosos han de formar parte del contenido esencial del derecho fundamental, asumiendo que la protección penal de esos sentimientos no ha de vincularse "a una determinada explicación trascendente de la vida o a la evitación de que el orden público y la paz religiosa se vea perturbada, sino a la dignidad que reviste la relación entre una persona y los valores que esa persona comparte y entiende trascendentes"; desde tal perspectiva, "cualquier escarnio intencionado y grave de las creencias, del culto o de la moral de una confesión para ofender dichos sentimientos, ha de ser considerado como antijurídico, porque la protección de los sentimientos religiosos frente al insulto es equivalente a un trato indigno o denigrante" ${ }^{17}$.

14. Véase, por ejemplo, Palomino, 2009, p. 539.

15. Cfr. en este sentido Garriga Domínguez, 2014, p. 103, quien alude a diversas voces doctrinales sin llegar a citarlas, pese a introducir párrafos entrecomillados.

16. Pérez Madrid, 2009, p. 23. En igual sentido, en su literalidad, Carrillo Donaire, 2015, pp. 238-239.

17. Pérez Madrid, 2009, p. 29; idéntico, Carrillo Donaire, 2015, pp. 238-239. En 
En mi opinión, tales planteamientos no se compadecen con el contenido protegido del derecho fundamental invocado, sino que, por el contrario, están basados en una distorsión de sus perfiles.

Con arreglo a la doctrina del Tribunal Constitucional, el derecho a la libertad religiosa posee una doble dimensión (SSTC 34/2011, de 28 de marzo; 192/2020, de 17 de diciembre). La interna "garantiza la existencia de un claustro íntimo de creencias y, por tanto, un espacio de autodeterminación intelectual ante el fenómeno religioso, vinculado a la propia personalidad y dignidad individual" (STC 177/1996, de 11 de noviembre). Esta vertiente, entendida como el derecho a profesar las creencias libremente elegidas o el derecho a no profesar ninguna, enlaza lógicamente con el derecho a la libertad ideológica pero también con el derecho a la intimidad, del que es expresión, en este ámbito, la garantía recogida en el artículo 16.2 CE, según la que "nadie será obligado a declarar sobre su ideología, religión o creencias"18. En segundo lugar, la dimensión externa del derecho es la que "que faculta a los ciudadanos para actuar con arreglo a sus propias convicciones y mantenerlas frente a terceros" y que se traduce "en la posibilidad de ejercicio, inmune a toda coacción de los poderes públicos, de aquellas actividades que constituyen manifestaciones o expresiones del fenómeno religioso" (STC 46/2001, de 15 de febrero).

Definido en esos términos su contenido, resulta, como digo, muy discutible que con las conductas de escarnio o profanación (arts. 524 y $525 \mathrm{CP}$ ) se restrinja o menoscabe el ejercicio del derecho a la libertad religiosa. Con las ofensas a símbolos o dogmas ni se impone coactivamente la asunción de determinada creencia, ni se impide la práctica de los ritos religiosos ${ }^{19}$. Por lo demás, ni se menoscaba la autonomía personal ni se restringen las posibilidades de participación equitativa en la vida social de los miembros de la comunidad religiosa.

sentido semejante, aunque restringiendo el merecimiento de pena a supuestos con suficiente gravedad como para afectar a la dignidad (sobre ello, infra), Bages Santacana, 2019, pp. 168, 189.

18. Vid. por ejemplo Garriga, 2014, p. 102; García Rubio, 2014, pp. 414 s.

19. En este sentido, por ejemplo, Martinez Torrón, 2015, pp. 27, 30; lópez guerra, 2013, pp. 89-90; García Rubio, 2014, pp. 414, 435; Vázquez Alonso, 2016, pp. 332 s. Cfr. también Hörnle, 2007, p. 396, quien distingue entre tipos penales de protección de sentimientos asociados a un derecho (como los delitos de amenazas o contra el honor) y de simple protección de sentimientos, incluyendo entre estos últimos al $\$ 166$ (trasunto del art. $525 \mathrm{CP})$. 
El menoscabo del derecho fundamental a la libertad religiosa solo se daría en el caso en que las conductas ofensivas conllevaran un componente coactivo o intimidatorio, que restringiera las posibilidades de libre formación de la voluntad o libre actuación; pero en tal caso los preceptos aplicables ya no serían los artículos 524 y $525 \mathrm{CP}$, sino los dos preceptos anteriores ${ }^{20}$. En definitiva, la libertad religiosa protege frente a la coacción externa dirigida a imponer o impedir la práctica religiosa, pero no abarca la indemnidad de tales creencias frente a la crítica o el oprobio; no establece un pretendido derecho a no sentirse ofendido ${ }^{21}$.

\section{2. ¿Dignidad?}

La apelación a la dignidad es recurrente en las posturas que pretenden incorporar los sentimientos subjetivos a la libertad religiosa, para con ello justificar su protección penal. Se afirma, por ejemplo, que el sentimiento religioso "es merecedor de tutela penal como expresión de la personalidad, como momento central de una dignidad por decir así existencial, como dato originario e inherente de la naturaleza humana. En este sentido, la protección penal no se presta en relación al reconocimiento emotivo con esta o aquella explicación trascendente de la vida, sino a la dignidad de la relación entre la persona y unos valores" 22 .

Y de la dignidad al derecho al honor solo hay un paso. Se sostiene, por ejemplo, que el sentimiento religioso haría referencia a "la sensación de apego con una creencia o idea que hace que ésta sea sentida como propia como parte de nuestro propio ser" ${ }^{23}$. Es decir, que harán referencia a un estado emocional de afecto que permite a las personas individuales identificarse íntimamente con sus creencias, convirtiéndose en auténticas convicciones que el sujeto siente como parte de su propia identidad. "Los sentimientos religiosos

20. Vid. Lascuraín Sánchez, 2016, pp. 179, 180. Véase también la reciente STC 192/2020, de 17 de diciembre, que confirma la condena por un delito de perturbación de actos religiosos del artículo $523 \mathrm{CP}$ considerando que en el caso concreto el derecho a la libertad religiosa primaba sobre la libertad de expresión.

21. García Rubio, 2014, p. 415.

22. Pérez Madrid, 2009, p. 24; Bages Santacana, 2019, p. 273: "los sentimientos religiosos son acreedores de tutela penal por ser un componente esencial de la personalidad y, por lo tanto, de la dignidad individual”.

23. Garriga Domínguez, 2014, p. 103, citando a Minteguía Arregui. 
o la autoestima religiosa, al igual que el derecho al honor, en la medida en que formarían parte de la identidad de las personas, estarían ligados a los valores de la integridad moral y en especial de la dignidad"24. Por ello, el escarnio a los sentimientos religiosos se convertirá en una auténtica ofensa a "elementos que el sujeto pasivo percibe como parte de su propia esencia como persona", lo que menoscabará su autoestima y supondrá antes la lesión del derecho al honor que de la libertad religiosa ${ }^{25}$.

Tampoco creo razonable concluir que el escarnio hacia símbolos religiosos afecte al honor o la dignidad de aquellos que, por identificarse con tales símbolos o credos, se sientan disgustados u ofendidos.

El fenómeno religioso puede concebirse de dos formas. Puede contemplarse, de una parte, como una práctica social compartida, de adscripción voluntaria, y basada en postulados con pretensión de verdad o de corrección axiológica. Pero también puede entenderse, y vivirse, como un vínculo identitario intenso que determina una cosmovisión y un código de conducta compartido ${ }^{26}$.

Esas dos formas de concebir la religión dependen en gran medida de la perspectiva que se adopte: desde un punto de vista interno a la comunidad religiosa, la vivencia subjetiva de la religión determinará en buena medida la propia identidad del individuo, de un modo quizá más intenso que otros constructos culturales como la nacionalidad o la etnia. Desde esa perspectiva, la religión será concebida como un fuerte vínculo con la comunidad en torno a un conjunto de dogmas sagrados e indiscutibles. Así lo han sostenido diversas voces provenientes del multiculturalismo, para quienes las creencias religiosas generan una cohesión de la comunidad, considerando que la identificación de la persona con los símbolos, credos y ritos que definen a esa comunidad llega hasta el punto de conformar la identidad personal de los feligreses, por lo que todo ataque a los símbolos se sentirá como un ataque a la propia identidad ${ }^{27}$.

La cuestión es si ese es el enfoque que debe adoptarse para contemplar el fenómeno religioso desde el ámbito jurídico-penal, o si debe asumirse, en cambio, un punto de vista externo y aconfesional, desde el que la identidad

24. Garriga Domínguez, 2014, p. 103.

25. Garriga Domínguez, 2014, p. 105, invocando a Minteguía Arregui (aunque sin citar la obra). En esta línea se enmarca también la posición de penalistas como Tamarit Sumalla, citado apud Roca Agapito, 2017, pp. 568-569.

26 Véase, en este sentido, Moon, 2018, pp. 1 ss., 61 ss., 90 ss.

27. Sobre ello, véase Alcácer Guirao, 2019, pp. 5, 10 ss. 
religiosa no posee mayor merecimiento de protección que otras comunidades identitarias y desde el que, al igual que otras cosmovisiones y otros códigos morales, los dogmas religiosos son susceptibles de crítica y rechazo.

La vinculación de la dignidad o el honor con el apego identitario a determinados símbolos culturales solo puede sostenerse desde la perspectiva interna a la comunidad religiosa: ante la intensa vinculación emocional con los símbolos, todo ataque a estos será vivido como un menoscabo a la propia autoestima, a la dignidad individual. Pero esa concepción no es admisible como base para configurar una política criminal racional. Frente a esa concepción, en un Estado liberal es fundamental distinguir entre la persona y sus creencias, entre la dignidad personal, inherente a todo ser humano por el hecho de serlo, y los constructos identitarios con los que cada uno se identifica.

El núcleo de sentido de la dignidad como valor jurídico fundamental (art. $10 \mathrm{CE}$ ) -siguiendo el clásico imperativo kantiano- es la expectativa de toda persona de ser tratada equitativamente como fin en sí mismo: la pretensión de reconocimiento del valor autónomo de toda persona en cuanto tal ${ }^{28}$. En palabras del Tribunal Constitucional, "la dignidad de la persona constituye una cualidad ínsita a la misma, que por tanto corresponde a todo ser humano con independencia de sus concretas características particulares" (STC 181/2004, de 2 de noviembre). Con la inclusión bajo su órbita prescriptiva de aquellos referentes culturales que dotan de identidad a individuos o comunidades, el concepto de dignidad se diluye y pierde su núcleo axiológico, pues en lugar de fundar el respeto incondicionado en aquello que es común a todos las personas se pretende proyectar sobre diferencias y particularidades propias de unos concretos grupos: en lugar de converger en la igualdad de todos, se pretende conformar sobre las diferencias; en lugar de garantizar lo esencial, se pretende extender a lo accidental, a lo adjetivo.

Frente a la citada comprensión multiculturalista, que identifica al yo con sus vínculos identitarios, al menos en el ámbito del Derecho penal -de un Derecho Penal liberal y democrático, huelga decir- es preciso establecer una nítida diferenciación entre la dignidad de la persona y aquellos patrones culturales que definen la identidad del grupo al que se adscriben, aun cuando en ocasiones la delimitación pueda resultar compleja.

28. Vid., por ejemplo, Waldron, 2012, pp. 59-60: “su status social básico, la base de su reconocimiento como seres iguales y titulares de derechos humanos constitucionalmente exigibles”. 
A ese respecto, es importante diferenciar entre aquellos atributos de identidad que son inherentes a la persona y aquellos que son fruto de una adscripción voluntaria y reflexiva: aquello que se es frente a aquello que se cree. En este sentido, mensajes de humillación basados en denigrar atributos de raza o género conllevarán un menoscabo más o menos intenso a la dignidad de la persona, porque ambos son inescindibles; no se menoscabará la dignidad de la persona, sin embargo, con la denigración o el escarnio de símbolos, profetas o relatos religiosos ${ }^{29}$.

Por ende, rechazable es también el abuso político-criminal en que se incurre con la interesada retórica de la dignidad. Apelar a un término tan cargado emocional y valorativamente -palabra tan excesiva que solo el silencio estaría a su altura, al decir de Jiménez Campo ${ }^{30}$ - pretende asignar un carácter indiscutible a la necesidad de proteger penalmente los sentimientos religiosos, al mismo tiempo que se enmascara la real dimensión axiológica de lo protegido. Con ello no solo se incurre en un puro intuicionismo argumental, sino que se genera una desproporcionada restricción de las libertades que se hallan en

29. En virtud de esa diferenciación, Timothy Garton Ash ha puesto de manifiesto que en realidad la religión debería merecer un menor grado de protección que características inmutables tales como el color o el género, por cuanto "no existen argumentos racionales contra el hecho de tener la piel oscura o clara, y no es posible cambiar de color de piel. En cambio, existen muchos argumentos racionales contra los presupuestos de cualquier religión, y uno puede elegir libremente su religión” (ASH, 2016, p. 255). De otra opinión es, por ejemplo, Minteguía, 2006, p. 29, afirmado que en el marco de los delitos contra los sentimientos religiosos, "la libertad de conciencia tendría como función dotar de un contenido material al derecho al honor, integrando en el ámbito de protección de este concepto no solamente elementos de carácter "originario" que identifican a la persona, como el sexo, la raza o la orientación sexual, sino también elementos dinámicos, como, por ejemplo, el ideológico, ya que una vez que conformamos en libertad nuestra propias convicciones, sean estas de carácter religioso o no, estas pueden pasar a formar parte de nuestra propia identidad y, por lo tanto, se integran en el objeto de protección del derecho al honor".

30. Jiménez Campo, 2018, p. 217. 
conflicto, estableciendo un criterio de lesividad -y de tipicidad penal, por tanto- de inmanejable vaguedad ${ }^{31} \mathrm{y}$ de insoportable maleabilidad ${ }^{32}$.

\subsection{Sentimientos y Derecho penal}

Descartada la protección de derechos, puede concluirse que el objeto de tutela del artículo $525 \mathrm{CP}$ - tal como, de hecho, refleja el título del capítulo del $\mathrm{CP}$ - son los sentimientos religiosos. Lo que se protege, en otras palabras, es el estado emocional derivado de la identificación de la persona con determinados símbolos considerados sagrados, y, por ello, asumidos como merecedores de respeto y veneración ${ }^{33}$. La ofensa a tales sentimientos se produce cuando, debido a esa íntima identificación, el escarnio de tales símbolos altera ese estado emocional generando reacciones emocionales de repulsa, indignación, aversión o rechazo ${ }^{34}$.

El atentado a los sentimientos religiosos tiene, así, una base psicológica, si bien no es preciso acreditar empíricamente que, en el caso concreto, se haya producido esa alteración emocional en una persona o grupo de personas para la afirmar la concurrencia del tipo penal; se parte, así, de una suerte de presunción de que burlas tenaces (tal es la definición de "escarnio" en el DRAE) o insultos graves a los símbolos, ritos o credos considerados sagrados por las religiones (oficiales) genera ese efecto sobre los creyentes. Por

31. Véase Bilbao Ubillos, 2018, p. 266: "el significado preciso de este concepto, de inconfundible aroma iusnaturalista y cargado de 'adherencias morales y antropológicas' (Jiménez Campo), es incierto. Y se corre el riesgo de caer en el puro 'intuicionismo' (R. Alexy). La determinación de su 'vaporoso contenido' es muy problemática: por un lado, puede encubrir una determinada ideología, 'casi siempre conservadora'; y por otro, su 'carácter ambivalente' podría conducir en ocasiones a 'resultados limitativos de la libertad' (F. Rey)".

32. Advierte Jiménez Campo, 2018, p. 218, del riesgo de que un criterio de contornos tan poco definidos pueda convertirse "sin réplica posible, en instrumento contramayoritario de una jurisdicción instituida en clase redentora”; añadiendo Bilbao Ubillos, 2018, p. 267, que, por ello, "podría ser un arma de grueso calibre en manos de jueces activistas".

33. Semejante, Bages SantacanA, 2019, p. 188.

34. En palabras de Minteguía, 2006, p. 28: "tutela de la relación afectiva de las personas individuales con respecto a las creencias que profesan y que están profundamente arraigadas en su conciencia frente a todos aquellos que mediante la realización de conductas o exteriorización de expresiones de carácter irreverentes tuviesen como objetivo atacar esas creencias y producir en el receptor una reacción emocional negativa”. 
otra parte, es fundamental poner de manifiesto que el objeto del delito no es la persona, sino los símbolos. El escarnio, la mofa, no se dirige hacia personas concretas, sino hacia los objetos de veneración. Y es la intensa identificación reverencial de la persona con los símbolos objeto de la burla lo que genera tales sentimientos. Afirma Minteguía en este sentido que, "de esta manera, el sujeto pasivo estimará que se ha llevado a cabo una ofensa contra su propia persona por la adhesión emocional que experimenta con respecto a las creencias objeto de escarnio, considerando, así, que estas son parte integrante de su propia identidad" 35 .Pero que la persona lo sienta como una afrenta personal no implica que deba social o jurídicamente asumirse como tal. Por ello rechazábamos que se esté protegiendo el derecho al honor o la dignidad con tales delitos.

Ese es, en última instancia, el mayor problema de la protección de los sentimientos religiosos: el componente subjetivo y emocional de tales sentimientos hace imposible sentar un estándar objetivo de la ofensa, esto es, un grado de lesividad evaluable por quienes no participan de la misma identidad religiosa, debiendo irremediablemente hacer depender la relevancia penal de la conducta de la sensibilidad subjetiva de los creyentes, o de patrones internos a la propia comunidad religiosa.

Así, solo caben dos parámetros posibles para establecer el grado de lesividad de la conducta expresiva: o bien asumir la perspectiva de la primera persona y evaluar la intensidad de la reacción de los ofendidos ${ }^{36}$, o bien adoptar una perspectiva cultural y analizar cuáles de los referentes culturales de la confesión religiosa resultan más valiosos para su identidad ${ }^{37}$. Pero en ambos casos la determinación de un estándar intersubjetivo de ofensividad resulta prácticamente inviable.

En relación con la primera opción, opone Boragno que "el principal problema es precisamente el hecho de que formulando nuestra queja en el lenguaje de la ofensa estamos afirmando únicamente una experiencia mental propia. Por tanto, el fundamento de la queja no puede comprobarse, sino que hemos de contentarnos con el informe en primera persona de aquel que se queja. Es decir, el lenguaje de la ofensa es incontrolable, en el sentido de que no hay manera de saber cuándo alguien sufre realmente una experiencia mental desagradable u ofensa. Además, las personas pueden ser más o me-

35. Minteguía, 2006, p. 28.

36. Boragno, 2014, p. 118.

37. Así, Pinto, 2010, p. 701. 
nos susceptibles de sentirse ofendidas" ${ }^{38}$. Y problemas semejantes plantea la segunda alternativa, si la ofensividad de la conducta se determina de modo enteramente dependiente de patrones de significado internos a la confesión religiosa, terminamos por poner en manos de la propia comunidad cultural la determinación de lo lesivo y, con ello, de lo penalmente relevante ${ }^{39}$. El problema en ambos casos es, en suma, que la medida de la ofensa depende de la sensibilidad del ofendido. Si a ello unimos el enorme grado de susceptibilidad inherente a creencias sostenidas en dogmas incontrovertibles y a la pretensión de sacralidad de sus símbolos culturales, desaparece toda posibilidad de encontrar un límite proporcionado a la aplicación de tipos penales de la índole del escarnio o la profanación.

Además, y desde el punto de vista de la tipificación del delito, tal imposibilidad de fijar criterios objetivables que concreten la lesividad exigible conllevará un insoportable grado de vaguedad en la descripción típica, difícilmente compatible con las garantías del derecho a la legalidad. Así, por más que pretenda desvincularse de la mera blasfemia exigiendo un específico ánimo de ofender ${ }^{40}$, lo cierto es que nada impide que el delito actualmente recogido en el artículo $525 \mathrm{CP}$ castigue conductas como la publicación de los Versos Satánicos o las caricaturas de Mahoma ${ }^{41}$.

Con independencia de tales aspectos, que hacen inviable una tipificación y aplicación racional del delito, el argumento esencial para rechazar la legitimidad del delito es que los sentimientos religiosos carecen de entidad suficiente para ser merecedores de protección penal. En un Estado democrático y liberal, el Derecho penal no está llamado a imponer estándares de decencia, moderación dialéctica, ni puede convertirse en la medida de lo políticamente correcto. Tampoco debe estar llamado a proteger la indemnidad de sensibilidades particulares, ni la integridad de identidades culturales, ni mayoritarias ni minoritarias. Por el contrario, solo deben ser castigadas aquellas ofensas

38. Boragno, 2014, p. 118.

39. Críticos con esa perspectiva, por ejemplo, Hörnle, 2012, p. 317; ASH, 216, pp. 217-218.

40. Así, Gimbernat, 2007, p. 19, n. 14. En sentido semejante Vázquez Alonso, 2016, p. 317, quien, no obstante, reconoce que estando ante un tipo penal "cargado de subjetivismo", resulta complicado determinar la existencia real de un daño.

41. Así, Atienza, 2007, p. 70. Ejemplo ilustrativo de ello son las piruetas argumentales que se ve obligada a hacer la jurisprudencia para llegar a un pronunciamiento absolutorio en casos como el de Javier Krahe u otros. Véase, por ejemplo, García Rubio, 2014, pp. 436 ss. 
graves inherentes a la dignidad humana - a lo que tenemos en común-que puedan generar un déficit relevante en las posibilidades de participación social de las personas.

Descartada su vinculación con el derecho a la libertad religiosa o a la dignidad, la protección de sentimientos religiosos solo podría legitimarse desde la previa atribución a la religión de un trato diferencial y privilegiado sobre otras creencias o convicciones. Pero, más allá de la experiencia interna del hecho religioso, de la vivencia subjetiva de lo sagrado, particularmente en un Estado que se define como aconfesional no puede justificarse ningún prius axiológico que legitime la protección reforzada de la identidad religiosa - de los vínculos emocionales con credos, dogmas o símbolos - frente a cualesquiera otras identidades, creencias o convicciones ideológicas ${ }^{42}$. Es debido a ello por lo que ha podido afirmarse que la protección de sentimientos religiosos se sostiene sobre una injustificable discriminación frente a otras convicciones ideológicas ${ }^{43}$. Frente a ello, la alternativa no es, ciertamente, ampliar el marco de protección penal a cualesquiera sentimientos o creencias (como, en el afán de evitar esa discriminación, torpemente ha intentado nuestro legislador incluyendo un inaplicable escarnio hacia los sentimientos de los no creyentes), sino derogar el precepto en cuestión.

\section{ESCARNIO Y LIBERTAD DE EXPRESIÓN}

Unido a lo expuesto, la ilegitimidad del delito de escarnio se debe, además, a que cercena desproporcionadamente el derecho fundamental a la libre expresión.

La libertad de expresión se fundamenta en el principio de autonomía política del ciudadano, consustancial al sistema democrático ${ }^{44}$ : el derecho a participar en la creación de las normas que a todos nos gobiernan presupone el derecho a intervenir en la deliberación sobre asuntos de relevancia pública ${ }^{45}$,

42. Niegan ese hecho diferencial autores como Gutmann, 2003, pp. 151 ss.; ASH, 2016, pp. 254-255.

43. Garcia Rubio, 2014, p. 435.

44. En palabras de Habermas, 1998, p. 69, "los ciudadanos son políticamente autónomos, así, sólo cuando pueden entenderse a sí mismos conjuntamente como autores de aquellas leyes a las que se someten como destinatarios”. Sobre el fundamento de la libertad de expresión que considero correcto, Alcácer, 2020, pp. 150 ss.

45. Cfr. Dworkin, 2011, p. 372 ss.; afirma en este sentido Weinstein, 2011, p. 498, 
tanto de modo directo, a través del voto y de la crítica sobre materias objeto de decisión política, como indirectamente, contribuyendo con la exteriorización de sus preferencias sociales, culturales o ideológicas a la conformación de la opinión pública ${ }^{46}$. A su vez, desde la perspectiva del auditorio, la exigencia de una deliberación pública racional presupone garantizar la más amplia información posible acerca de las diferentes opciones ideológicas, pues solo de ese modo las decisiones del ciudadano acerca de cómo quiere ser gobernado podrán considerarse racionales y razonables ${ }^{47}$. Tal fundamento determina el contenido del derecho fundamental: la libertad de expresión no garantiza cualquier manifestación personal -no garantiza decir lo que a cada uno le venga en gana-, sino únicamente a difundir aquellos discursos dotados de relevancia pública, lo que genéricamente -y en el sentido amplio aludido- podemos calificar como discurso político; solo ese discurso político vendrá constitucionalmente reforzado por la "posición preferente" que el Tribunal Constitucional ha venido asignando a la libertad de expresión (SSTC 159/1986, de 16 de diciembre; 235/2007, de 7 de noviembre).

Desde tales premisas, puede afirmarse que el discurso antirreligioso se incardina bajo el ámbito del discurso político y, por tanto, bajo el contenido prima facie protegido por la libertad de expresión ${ }^{48}$. El papel que la religión se atribuye de custos morum, de guardián de las costumbres, y su decisiva influencia en la fijación de la agenda ideológica en materias de tal calado público como el aborto, la eutanasia, el uso de medios anticonceptivos, las opciones de género, etc., convierten a las Iglesias (en nuestro país, señaladamente a la Iglesia católica) en actores políticos de primer orden. Por más que el sentimiento religioso pueda considerarse individual y privado, las doctrinas y credos religiosos presentan una dimensión pública y política

que "el derecho a participar en la discusión pública sin restricciones de contenido por parte del gobierno no es sólo un interés colectivo inherente a la soberanía popular, sino que conforma un derecho fundamental del individuo".

46. Para una aproximación a las dinámicas de la opinión pública y la relevancia de la libertad de expresión, véase Alcácer, 2020, pp. 138 ss.

47. Cfr. Rawls, 1996, pp. 52, 88 ss., considerando la libertad de expresión como una de las libertades básicas, presupuesto, por tanto, de una deliberación racional y razonable. Ello ha sido reiteradamente enfatizado por nuestro Tribunal Constitucional, manifestando que "para que el ciudadano pueda formar libremente sus opiniones y participar de modo responsable en los asuntos públicos, ha de ser también informado ampliamente de modo que pueda ponderar opiniones diversas e incluso contrapuestas" (SSTC 159/1986, de 16 de diciembre; 235/2007, de 7 de noviembre).

48. Sobre esa idea de la protección prima facie, véase Alcácer, 2020, pp. 202 ss. 
innegable ${ }^{49}$. Desde tales premisas, puede afirmarse sin lugar a dudas que el discurso antirreligioso presentará por lo general relevancia pública -afectará a asuntos relacionados con el autogobierno o con pautas intersubjetivas de conducta- y que, por tanto, entra dentro del contenido prima facie protegido por la libertad de expresión. En efecto, el discurso antirreligioso, incluso el canalizado a través de la burla o el escarnio, conllevará un componente crítico, reivindicativo o emancipador propio del discurso político, inserto en los contornos del derecho fundamental. Por ello, la prohibición bajo pena del escarnio de símbolos o credos religiosos o bien restringirá el ejercicio del derecho fundamental a la libre expresión - unido a otros, cercanos, como el de libertad de creación artística-, o bien, en todo caso, disuadirá coactivamente de tal ejercicio, al prohibir conductas situadas en los márgenes de su contenido protegido. Ese inconstitucional desaliento de la libertad de expresión resultará, además, particularmente intenso -y, por ello, desproporcionadodada la inevitable vaguedad e indeterminación que caracteriza a preceptos de esta índole ${ }^{50}$.

Puede concluirse que la constitucionalidad del delito de escarnio a los sentimientos religiosos resulta por ello muy cuestionable.

\section{ESCARNIO Y DISCURSO DEL ODIO}

\subsection{Creencias y creyentes}

Tras la controversia sobre los límites de protección de los sentimientos religiosos late una diferente comprensión del fenómeno religioso y su

49. Vázquez Alonso, 2016, p. 333; March, 2012, pp. 25-26. Suscribo palabra por palabra el planteamiento de Enrique Gimbernat en este aspecto (Gimbernat, 2007, p. 20): “Las 'Weltanschauungen' -y la religión es una 'Weltanschauung' más- tienen que poder ser objeto de crítica sin límite alguno, porque, si son ciertas, merecen el respeto sólo de quienes las profesan personalmente, y, si no lo son, entonces se trata de grandes estafas intelectuales y tiene que ser posible que los que alguna vez se sintieron estafados, o tratan de evitar que otros incurran en ese fraude, puedan expresar, si así lo tienen por conveniente, qué miserable opinión les merece cualquiera de las 'cosmovisiones' -también las religiosas a las que acabo de hacer referencia-, sin que el Derecho penal esté autorizado para inmiscuirse en polémicas que están y deben seguir estando abiertas”.

50. Lo mismo puede decirse, por ejemplo, del delito de ofensas o ultrajes a los símbolos patrios (art. $543 \mathrm{CP}$ ). Sobre la directa relación entre el déficit de taxatividad de la ley y el efecto desaliento, cfr. Cuerda Arnau, 2007, pp. 25 ss.; ALcácer, 2020, pp. 202 ss. 
relevancia para la identidad personal. Quienes lo asumen como un vínculo constitutivo de la persona -inherente con ello a la dignidad-suelen reprochar al sector opuesto -el que lo concibe como una adscripción voluntaria y convencional- su incapacidad de entender lo que "realmente" es la vivencia del hecho religioso y, por ello, de aprehender el impacto emocional que los creyentes suponen los mensajes hostiles a su religión.

Ese profundo desencuentro se planteó de modo especialmente virulento con ocasión de las caricaturas de Mahoma. Más allá de las reacciones violentas acontecidas en países islámicos, tras su publicación en el Jyllands-posten danés surgieron diversas voces en la academia de diversos países europeos formulando reproches de incomprensión e insensibilidad sobre la trascendencia que la representación del profeta tenía para los musulmanes y para su propia estima como miembros de esa comunidad religiosa ${ }^{51}$.

La dificultad de comprensión que se atribuye a los extraneus a la vivencia religiosa, y que se invoca como fundamento de la restricción del discurso ofensivo, constituirá en realidad uno de los mayores problemas para una aplicación racional de las normas destinadas a proteger los sentimientos religiosos, precisamente por la subjetividad de tales sentimientos y la incapacidad para sentar un estándar objetivo de lesividad. De cualquier modo, lo que en este momento me interesa destacar es que esa identificación entre creencias religiosas e identidad de la persona, y la asunción de tales creencias y prácticas como elementos constitutivos de su estima social y su dignidad, conllevará la imposibilidad no ya de distinguir el discurso crítico contra la religión y el discurso ofensivo, sino incluso la de diferenciar entre las ofensas a los sentimientos religiosos y la incitación al odio o la discriminación ${ }^{52}$, pues desde esa óptica toda crítica procaz $u$ ofensiva hacia creencias y figuras sacras se interpretará - se sentirá - como una manifestación de menosprecio hacia la identidad personal y el estatus social de los miembros de la religión.

Como ya he afirmado, a mi entender debe rechazarse que en las ofensas a la religión se vea menoscabada la dignidad de los miembros de la confesión religiosa, y ello con independencia de lo intensas que puedan ser las emociones de oprobio o indignación. Sin perjuicio de ello, aun asumiendo en un plano teórico esa diferenciación entre el ámbito de los sentimientos subjetivos y el contenido de la dignidad o el honor personal, en ocasiones no

51. Sobre ello, con amplitud, puede verse la obra colectiva de Asad/Brown/Butler / Mahmood, 2009. Cfr. también march, 2012, p. 3; Danchin, 2010, p. 10.

52. March, 2012, p. 3 
será fácil trazar la línea que media entre la humillación a los creyentes y a las creencias; entre la ofensa a una persona, o a un grupo de personas, debido a sus creencias religiosas - caso en el que, por difusa que se antoje la idea, sí podría ser posible afirmar un menoscabo de la dignidad-y la "humillación" a sus creencias religiosas.

Tal diferencia entre el ataque al creyente y el ataque a las creencias será relevante no solo en un plano especulativo, sino también porque es la que permite delimitar las conductas de escarnio recogidas en el artículo $525 \mathrm{CP}$ de las que, con penas más graves, estarían incluidas en el artículo $510 \mathrm{CP}$ como supuestos de incitación al odio y a la discriminación.

La vis expansiva de la noción de "discurso de odio" ha terminado por atribuir tal etiqueta peyorativa a todas aquellas conductas expresivas que generan reacciones sociales adversas, con el fin de declararlas excluidas del ejercicio de la libertad de expresión y justificar, así, su punición ${ }^{53}$. En particular, en ocasiones se ha pretendido legitimar el delito de escarnio a los sentimientos religiosos atribuyéndole tal carácter de discurso de odio, considerando que genera una incitación al odio de los creyentes, o bien -como hemos visto- asumiendo que en ambos casos es el mismo el interés lesionado, ya sea la dignidad, el honor o la libertad religiosa ${ }^{54}$. A fin de evitar esa interesada confusión, es importante delimitar con claridad supuestos que, aunque en ocasiones se entremezclen, presentan contornos diversos, tanto desde un plano sociológico como jurídico ${ }^{55}$.

La necesidad de distinguir ambos fenómenos se debe, además, a la diferente legitimidad que, en el consenso internacional, presenta la protección de sentimientos religiosos frente a la incitación al odio o la discriminación. Ello aparece con claridad, por ejemplo, en el Informe de la Comisión Venecia sobre la relación entre la libertad de expresión y la libertad religiosa, de octubre de $2008^{56}$. En el informe se parte de que "las fronteras entre el insulto

53. Ampliamente sobre el uso y abuso del término “discurso del odio”, Alcácer Guirao, 2020, pp. 23 ss.

54. Vid., por ejemplo, Pérez Madrid, 2009, pp. 22-23.

55. Los distingue con claridad, por ejemplo, Vázquez Alonso, 2016, p. 308, al plantearse la cuestión de "qué respuesta jurídica ha de darse en aquellos supuestos en los que el discurso no constituye un ataque a la reputación o al estatus social de los creyentes, sino un ataque contra sus creencias o contra los dogmas y símbolos de su fe". Véase también, pp. 337 ss.

56. European Commission For Democracy Through Law (Venice Commission), Report on the relationship between freedom of expression and freedom of religion: the issue of regulation and prosecution of blasphemy, religious insult and incitement to reli- 
a los sentimientos religiosos (incluso la blasfemia) y el discurso del odio son fácilmente difuminables, siendo por ello difícil de establecer dónde se halla la línea que separa la expresión de ideas y la incitación al odio" (\$ 68). Pero esa diferenciación es esencial, porque si bien "el discurso de odio justifica la sanción penal” ( $\mathbb{5} 57)$, la Comisión "no considera necesario o deseable crear un delito de insultos religiosos (es decir, de insultos a los sentimientos religiosos) si carece de la incitación al odio como elemento esencial” ( $\mathbb{S} 64)$. Y concluye: "si una expresión o una obra artística no puede ser considerada como incitación al odio, no debería ser objeto de sanciones penales” ( $\mathbb{S} 64)$.

También la Recomendación de Política General nº 15, de la Comisión Europea contra el Racismo y la Intolerancia (ECRI), del Consejo de Euro$\mathrm{pa}^{57}$, pone de manifiesto que "la lucha contra el discurso de odio debe servir para proteger a las personas y grupos de personas más que a credos, ideologías y religiones en concreto" (p. 10). De modo semejante, el Plan de Acción de Rabat, elaborado por un taller de expertos a instancia de la Oficina del Alto Comisionado para los Derechos Humanos de la $\mathrm{ONU}^{58}$, destaca que "las leyes que castigan la blasfemia son contraproducentes, ya que pueden dar lugar a una censura de facto de los diálogos, debates y críticas interreligiosos e intrarreligiosos, la mayoría de los cuales podrían ser constructivos, saludables y necesarios" y que "el derecho a la libertad de religión o de creencias, tal como está consagrado en las normas legales internacionales pertinentes, no incluye el derecho a tener una religión o una creencia que esté libre de críticas o burlas” ( $\mathbb{S} 19)$.

En suma, es fundamental diferenciar ambos fenómenos, tanto desde un plano de lege ferenda como de lege lata; así, por ende, resultan mucho más graves las conductas propias del discurso del odio que las de escarnio a los

gious hatred, Study no. 406/2006. Adoptada por la Comisión de Venecia en la Comisión Plenaria 76 (17-18 de octubre 2008).

57. Recomendación de política general $n^{\circ} 15$ relativa a la lucha contra el discurso de odio y memorándum explicativo. Disponible en: http://www.mitramiss.gob.es/oberaxe/ es/publicaciones/documentos/documento_0002.htm

58. "Plan de Acción de Rabat sobre la probibición de la apología del odio nacional, racial o religioso que constituye incitación a la discriminación, la hostilidad o la violencia", adjunto al Informe del Alto Comisionado de las Naciones Unidas para los Derechos Humanos acerca de los talleres de expertos sobre la prohibición de la incitación al odio nacional, racial o religioso, A/HRC/22/17/Add.4, de 11 de enero de 2013. Disponible en: https://www.ohchr.org/Documents/HRBodies/HRCouncil/RegularSession/ Session22/A-HRC-22-17-Add4_sp.pdf 
sentimientos religiosos (tal como se evidencia con la diferencia de pena existente entre los artículos $510 \mathrm{CP}$ y $525 \mathrm{CP}$ ).

Para intentar esa delimitación, lo primero es determinar la noción de discurso de odio. A tal fin, podemos servirnos del concepto de discurso de odio comúnmente empleado, tal como aparece recogido en la Recomendación 97 (20) del Comité de Ministros del Consejo de Europa:

cualquier forma de expresión que propague, incite, promueva o justifique el odio racial, la xenofobia, el antisemitismo u otras formas de odio basadas en la intolerancia, la discriminación y la hostilidad contra las minorías y los inmigrantes.

Más amplia es la descripción que acoge la Recomendación no 15 de la Comisión Europea contra el Racismo y la Intolerancia (ECRI), publicada el 21 de marzo de 2016, sobre "Líneas de actuación en relación con la lucha contra las expresiones de incitación al odio":

el discurso de odio debe entenderse como fomento, promoción o instigación, en cualquiera de sus formas, del odio, la humillación o el menosprecio de una persona o grupo de personas, así como el acoso, descrédito, difusión de estereotipos negativos, estigmatización o amenaza con respecto a dicha persona o grupo de personas y la justificación de esas manifestaciones por razones de "raza", color, ascendencia, origen nacional o étnico, edad, discapacidad, lengua, religión o creencias, sexo, género, identidad de género, orientación sexual y otras características o condiciones personales.

Interesa destacar dos aspectos de esas amplias definiciones. El primero es que el discurso de odio tiene como destinatarios a los miembros de determinados colectivos en virtud de sus características. El rechazo, la hostilidad, el insulto, se dirige contra las personas adscritas a determinados colectivos identitarios, no contra los constructos culturales que vehiculan esa identidad. Expresado en términos más sintéticos: la incitación al odio religioso se dirigiría contra los creyentes, no contra las creencias; contra las personas, no contra los símbolos.

El segundo atiende al núcleo de sentido del discurso de odio: tal como explícitamente se recoge en las Recomendaciones, la característica esencial del discurso de odio radica en la manifestación pública de discriminación hacia determinadas personas o grupos sociales en atención a las características que identifican y distinguen a sus miembros, pero únicamente cuando tales grupos sociales deban ser protegidos en atención a esas características por 
haber venido siendo objeto históricamente de discriminación social o exista, en todo caso, un contexto social previo de marginación.

Es ese citado componente discriminatorio, característico de los colectivos destinatarios de la hostilidad, lo que permite distinguir el "discurso del odio" de otras conductas expresivas de rechazo, oprobio o denigración contra personas o colectivos, y es lo que motiva -justificadamente o no- la restricción de la libre expresión pública presente en los textos internacionales. Así lo entiende también, por ejemplo, la organización no gubernamental especializada en libertad expresión “Article 19". En su informe de 2015 titulado 'Hate Speech' Explained. A Toolkit, intentando encontrar un concepto de mínimos a partir de la noción de "odio", se concluye que el discurso del odio no ha de equipararse con la expresión de un sentimiento de rechazo o aberración, sino que el mensaje debe tener un componente discriminatorio, en tanto en cuanto debe estar dirigido contra personas o grupos identificados por determinadas “características protegidas” por el Derecho internacional.

Ambos aspectos son decisivos para distinguir las conductas de discurso de odio antirreligioso de las que puedan constituir ofensas a símbolos o credos. No estamos ante el mismo fenómeno cuando se cocina un Cristo, se quema una biblia o se divulga una imagen de Mahoma como un pederasta o un borracho, que cuando se difunden estereotipos como que los judíos son seres inferiores o que todos los musulmanes son terroristas. Con independencia del tratamiento politicocriminal que, de lege ferenda, deba darse a estos últimos supuestos - cuestión que no es objeto de estas páginas ${ }^{59}-$, la creación de estereotipos que sean idóneos para fomentar el repudio social o la discriminación presentan cierto grado de afectación a la dignidad de los miembros del grupo ${ }^{60} \mathrm{y}$, de lege lata, encajarían en los dos primeros apartados del artí-

59. En Alcácer Guirao, 2020, passim, he intentado desarrolla un programa político criminal para el discurso del odio.

60. Así lo entiende, por ejemplo, Jeremy Waldron, quien es partidario de sancionar la difamación colectiva. Desde su concepción liberal, lo protegido no es, como tal, el grupo -su supervivencia, su cohesión, su cultura-, sino cada uno de sus miembros, que ven su reputación social menoscabada cuando públicamente se menosprecian las cualidades o características comunes a todos (Waldron, 2012, pp. 60,122). Esa difamación de grupo puede venir dada cuando se atribuyen hechos calumniosos que conllevan un impacto directo en el estatus social de los miembros del grupo -todos los gitanos son ladrones, todos los musulmanes son terroristas-; cuando se degradan o menosprecian gravemente las características inherentes a los miembros del grupo y que los definen como tal grupo étnico, religioso, etc. -los negros son monos; los judíos son una raza inferior, los homosexuales son enfermos mentales, etc.-; o cuando se propagan mensajes que promueven la 
culo 510 CP. Sin embargo, el primer grupo de conductas no afectan al estatus reputacional de los miembros del grupo religioso, ni reducen sus posibilidades de participación social, sino que únicamente pueden conllevar una ofensa basada en sus representaciones de lo sagrado y sus patrones culturales.

El problema es que, en la práctica, no es tarea fácil delimitar ambos supuestos $^{61}$. Sirvámonos como ejemplo del famoso caso de las caricaturas de Mahoma publicadas en el Jyllands-Posten.

Con carácter general, en dichas caricaturas podrían distinguirse tres formas de discurso ofensivo, de menor a mayor gravedad:

i. (Blasfemia) De una parte, la sola representación de la imagen de Mahoma constituye, para algunas versiones del islam, un insulto contra el profeta; estaríamos ante el quebrantamiento de un tabú religioso, o ante un supuesto de blasfemia ${ }^{62}$.

ii (Escarnio) En segundo lugar, la burla de creencias o tradiciones religiosas, como el chiste sobre la expectativa de las vírgenes en el cielo, constituiría una modalidad de escarnio. Más dudas podría plantear la interpretación de la imagen de Mahoma con una cimitarra en actitud agresiva y protectora contra dos mujeres con velo integral que se hallan detrás de él: ¿constituye una crítica contra la sumisión de la mujer en la religión musulmana? ¿pretende trasladar, además, la idea de que Mahoma era un ser violento? ¿O aspira más bien a fomentar el estereotipo de que todos los musulmanes son violentos y agresivos contra sus mujeres?63.

iii (Incitación al odio) La caricatura más controvertida fue, en todo caso, la que representaba a Mahoma con un turbante del que emana una bomba, en la que aparecía inscrita la shahadah. A diferencia de las anteriores, podría decirse que esta caricatura se dirige antes contra los musulmanes que, contra el islam, contra los creyentes antes que contra la creencia ${ }^{64}$. Siguiendo esa estela de pensamiento, sería razonable interpretarla como una identificación entre la

discriminación de tales grupos en atención a sus características - moros fuera, los negros no son bienvenidos, etc.-(Waldron, 2012, pp. 56 ss.). Esos ataques reputacionales, afirma Waldron, atentan contra la dignidad de las personas, entendida "como su status social básico, la base de su reconocimiento como seres iguales y titulares de derechos humanos constitucionalmente exigibles" (Waldron, 2012, p. 59). Una exposición crítica sobre la propuesta de este autor en Alcácer, 2016, pp. 44 ss. 64 ss.

61. En este sentido, por ejemplo, Martínez-Torrón, 2015, p. 27; Moon, 2018, pp.

62. Brahm Levey/Modod, 2009, p. 431-432.

63. Sobre la dificultad interpretativa de esa caricatura, cfr. Bleich, 2012, p. 118, concluyendo que, como mínimo, identifica a Mahoma con una tendencia a la violencia y a la opresión contra las mujeres.

64. Sobre ello, véase Brahm Levey/Modod, 2009, pp. 435 ss., 439 ss. 
religión musulmana y el terrorismo, y entender por ello que tenía cierta virtualidad discriminatoria, y lesiva del estatus social del grupo, al fomentar un estereotipo muy negativo sobre todos los musulmanes. Estaríamos, por ello, en el ámbito del discurso del odio, ya como un supuesto de incitación al odio o discriminación (art. 510.1 CP), ya de difamación de grupos (art. 510.2 CP).

Como síntesis de lo expuesto, podríamos decir que diseminar estereotipos degradantes de una comunidad religiosa constituirá una modalidad de incitación al odio, que de lege lata podrá ser incardinada bajo el artículo 510 $\mathrm{CP}$ cuando alcance gravedad suficiente para potencialmente menoscabar la estima social del grupo y, con ello, la dignidad de sus integrantes. Sin embargo, el menosprecio de símbolos u objetos de veneración constituirá una mera ofensa a los sentimientos religiosos.

Pero esa diferenciación genérica no resuelve los problemas de delimitación. La particularidad de la identidad religiosa es que símbolos y doctrinas están tan imbricados con el modo de vida de los participantes de la religión que muchas veces el desprecio a los símbolos podrá generar un efecto reputacional negativo de la comunidad en su conjunto. Piénsese en los casos de generalización a toda la comunidad de las prácticas de un grupo reducido de la misma - "todos los musulmanes son terroristas" -, o en la falsa atribución a la propia doctrina religiosa del fomento de prácticas moralmente rechazables - "el catolicismo fomenta la pederastia" - ${ }^{65}$. Cuando se divulga que Mahoma era un pedófilo - como en el caso resuelto en la Sentencia del Tribunal Europeo de Derechos Humanos E.S. c. Austria- es claro que nos hallamos en el ámbito de la blasfemia o, en su caso, del escarnio; pero cuando se divulga que, al ser Mahoma un modelo de vida para los musulmanes, el islam defiende, promueve o siquiera incluye la pedofilia entre sus dogmas, podríamos estar ante un supuesto de incitación al odio. El problema es que el predominio de uno u otro mensaje en la conducta expresiva dependerá de matices interpretativos muy difíciles de diferenciar.

\section{DiSCURSO DE ODIO Y RELIGIONES HEGEMÓNICAS}

En la delimitación de ambos fenómenos sociales - y delitos - es preciso ponderar un factor adicional. Como hemos visto, un elemento inherente a la definición del discurso de odio -plasmado también en la descripción típica

65. Moon, 2018, p. 65. 
de preceptos como el $510 \mathrm{CP}$ - es la marginación o discriminación inherente a los grupos diana, contra los que se dirige el discurso hostil. Desde esa perspectiva, a la hora de delimitar entre discurso de odio y mero escarnio/blasfemia deberá tenerse en cuenta la posición social que ocupe el grupo religioso: la balanza se orientará más hacia el discurso de odio si estamos ante grupos minoritarios que si las ofensas se producen sobre religiones mayoritarias o hegemónicas.

Ello ha sido destacado por diversos autores. La misma idea plantea, por ejemplo, Martínez-Torrón. A su juicio, esa diferenciación es fundamental porque mientras el discurso de odio debería ser punible, el ultraje a ideas, símbolos ritos o personajes sagrados no debe merecer reproche penal. Así, será preciso acudir a la vía penal únicamente "cuando la ofensa proferida no se limita a herir los sentimientos de determinados fieles, sino que dañan seriamente la reputación de una confesión religiosa o de sus miembros, produciendo así situaciones de discriminación o dificultando que algunos ciudadanos practiquen libremente su religión”. Y a continuación pone de relieve que eso "es más fácil que suceda con minorías religiosas -por lo general más vulnerables a las consecuencias de la difamación- que con la religión mayoritaria" "66. En sentido semejante, sostiene Moon que "el impacto de los insultos antirreligiosos será mayor cuando los miembros del grupo diana se sienten ya discriminados e interpretan el mensaje como un refuerzo simbólico de su situación de subordinación en sociedad" ${ }^{67}$.

Desde otra perspectiva -nítidamente multiculturalista-, Meital Pinto acoge también un planteamiento semejante. Su punto de partida es que las ofensas a los sentimientos religiosos deben contemplarse desde la óptica de la lucha por la igualdad entre grupos culturales, y que el criterio de enjuiciamiento ha de ser un "principio de vulnerabilidad de la identidad cultural", en el sentido de que "cuanto más vulnerable sea la identidad cultural del grupo, mayor gravedad tendrá la ofensa a la integridad de la identidad cultural”68. Así, la lesividad de las ofensas no debe analizarse "en términos subjetivos relativos a cuántas personas se han sentido ofendidas, sino en términos relativos al grado en que se ha podido dañar su estatus de igualdad en sociedad"69. Desde tales premisas, las ofensas proferidas contra una religión mayoritaria

66. Martínez-Torron, 2016, p. 30.

67. Moon, 2018, p. 94.

68. Pinto, 2010, pp. 697, 704.

69. Pinto, 2010, pp. 698, 706. 
no causarán un daño relevante, puesto que no pondrán en peligro su estatus social ni la integridad de su identidad cultural. Mayor gravedad presentará, sin embargo, el escarnio o desprecio a los símbolos de una comunidad religiosa minoritaria, puesto que incidirá negativamente en el ya vulnerable estatus social de la comunidad, menoscabando con ello su identidad cultural ${ }^{70}$.

Creo que puede compartirse la premisa, pero no las consecuencias que extrae Pinto. La condición de grupo minoritario no puede, per se, conllevar que las ofensas religiosas adquieran gravedad suficiente como para merecer reproche penal. Dicho de otro modo, ante conductas de escarnio de entidad semejante-quemar una biblia y quemar un Corán, insultar a Cristo o insultar a Mahoma, etc.-, no debe considerarse que las dirigidas a un grupo minoritario resulten más graves. Ya he puesto de manifiesto que lo protegido por el delito de escarnio no guarda relación ni con la dignidad ni, menos aún, con la prevención de la discriminación, por lo que no puede ser ese el fundamento de la mayor gravedad. Por descontado, tampoco una conducta de mera ofensa a símbolos religiosos puede transmutarse en un supuesto de discurso de odio - una incitación al odio, un menoscabo grave de la dignidad- por la sola razón de que estemos ante grupos religiosos minoritarios.

Sin embargo, el castigo del discurso del odio - el artículo $510 \mathrm{CP}-$ sí tiene por finalidad prevenir la discriminación de personas y colectivos, por lo que, una vez en ese ámbito, sí habrá de tener relevancia la situación social del grupo. De una parte, sí puede conllevar que, en aquellos casos límite, la conducta pueda calificarse como discurso de odio, antes que como mero escarnio. A esto se refiere Martínez-Torrón, entiendo, cuando manifiesta que en casos de discurso antirreligioso será más fácil apreciar la existencia de una incitación a la discriminación si estamos ante un grupo minoritario.

De otra parte, la conclusión que puede también sacarse es que, inversamente, un grupo religioso hegemónico no podrá ser víctima idónea del discurso de odio. Expresado de otro modo, y ciñendo la cuestión a la situación social y jurídica española: si, como creo razonable desde su fundamento de protección, efectuamos esa interpretación teleológica del artículo $510 \mathrm{CP}$ y concluimos que sus conductas típicas solo son aplicables ante el discurso hostil o difamatorio de grupos minoritarios o tradicionalmente sometidos a discriminación, los miembros de la religión católica no pueden, en nuestro país, ser sujetos pasivos del precepto. Las conductas difamatorias contra la religión católica, ya contra las creencias ya contra los creyentes, solo podrán

70. Pinto, 2010, pp. 717 ss. 
constituir, a lo sumo, un delito de escarnio o, en su caso, un delito de injurias o calumnias, pero no encajará en el artículo $510 \mathrm{CP}$.

Este planteamiento seguramente resulte polémico para algunos sectores, pero no debería sorprender: tampoco debería sorprender la exclusión del artículo $510 \mathrm{CP}$ de discursos dirigidos contra la comunidad de raza blanca, contra los heterosexuales o contra los hombres (como grupos sociales hegemónicos), ni la exclusión de los discursos dirigidos contra policías, jueces o toreros (como grupos sociales no discriminados).

\section{REFERENCIAS BIBLIOGRÁFICAS}

Alcácer Guirao, R. (2020). La libertad del odio. Madrid.

Alcácer Guirao, R. (2019). "Símbolos y ofensas. Crítica a la protección penal de los sentimientos religiosos”, Revista Electrónica de Ciencia Penal y Criminología 21, pp. 1 ss.

Alcácer Guirao, R., "Diversidad cultural, intolerancia y derecho penal”. Revista Electrónica de Ciencia Penal y Criminología, no 18-11 (2016), pp. 1 ss.

Asad, T./Brown, W./Butler, J./Mahmood, S. (2009). Is Critique Secular? Blasphemy, Injury, and Free Speech, Berkeley.

Ash, T.G. (2016). Free Speech, London.

Atienza, M. (2007). "Las caricaturas de Mahoma y la libertad de expresión", Revista internacional de filosofía política 30, pp. 65 ss.

Bages Santacana, J. (2019). La protección penal de los sentimientos religiosos, Valencia.

Bilbao Ubillos, J. M. (2018). Artículo 10.1, en: Pérez Tremps, P./Saiz Arnaiz, A. (directores), Comentario a la Constitución Española, Libro Homenaje a Luis López Guerra, Tomo I, Valencia, pp. 263 ss.

Bleich, E., "Free Speech or Hate Speech? The Danish Cartoon Controversy in the Europe Legal Context". (2012). en Khory, Kavita R., Global Migration: Challenges in the Twenty-First Century, pp. 113 ss.

Brahm Levey, G. y Modood, T. (2009). "The Muhammad cartoons and multicultural democracies”, Ethnicities 9, pp. 427 ss.

Boragno Gil, I. (2014). "Libertad de expresión, ofensa y religión”, Bajo Palabra. Revista de Filosofía 9, pp. 113 ss.

Carrilo Donaire, J.A. (2015). “Libertad de expresión y 'discurso de odio’ religioso: la construcción de la tolerancia en la era postsecular”, Revista de Fomento Social 70, pp. 205 ss.

Cuerda Arnau, M. (2007). "Proporcionalidad penal y libertad de expresión. La función dogmática del efecto desaliento", Revista General de Derecho Penal 8, pp. 1 ss. 
Danchin, P. (2010). "Defaming Muhammad: dignity, harm, and incitement to religious hatred", Duke Forum for Law E Social Change 5, pp. 4 ss.

DwORKIN, R. (2011), Justice for Hedgehogs, Cambridge.

García Rubio, M. P. (2014). “Arte, religión y Derechos Fundamentales. La libertad de expresión artística ante la religión y los sentimientos religiosos (algunos apuntes al hilo del caso Javier Krahe)", Anuario de Derecho Civil 67, pp. 397 ss.

Garriga Dominguez, A. (2014) "El conflicto entre la libertad de expresión y los sentimientos religiosos en las sociedades multiculturales", Anuario de Filosofía del Derecho 30, pp. 97 ss.

Gimbernat Ordeig, E. (2007). "Presentación”, en Hefendehl (ed.), La teoría del bien jurídico. ¿Fundamento de legitimación del Derecho Penal o juego de abalorios dogmático? Madrid/Barcelona, pp. 18 y ss.

Gutmann, A. (2003), Identity in Democracy, Princeton.

Habermas, J. (1998), Facticidad y Validez, Madrid.

Hörnle, T. (2012). "Criminalizing Behaviour to Protect Human Dignity", Criminal Law and Philosophy 6, pp. 307 ss.

Hörnle, T. (2007) "La protección de sentimientos en el StGB", en Hefendehl (ed.), La teoría del bien jurídico. ¿Fundamento de legitimación del Derecho Penal o juego de abalorios dogmático? Madrid/Barcelona, pp. 383 ss.

Hume, M. (2015). Trigger Warning. Is the fear of being offensive killing free speech, Londres.

Jiménez CAmpo, J. (2018). Artículo 10, en: Casas/Rodríguez-Piñero, Comentarios a la Constitución Española, Madrid, pp. 213 ss.

Lascurain SÁnchez, J. A. (2016). "Proporcionalidad penal”, Maqueda Abreu/Martín Lorenzo/Ventura Püschel (coord.), Derecho Penal para un Estado social y democrático de Derecho: estudios penales en homenaje al profesor Emilio Octavio de Toledo y Ubieto, Madrid, UCM, Madrid, pp. 175 ss.

LópeZ-SidRo López, A. (2016). "La libertad de expresión de la jerarquía eclesiástica y el discurso del odio", Revista General de Derecho Canónico y Derecho Eclesiástico del Estado 42, pp. 1 ss.

March, A. F. (2012), "Speech and the Sacred: Does the Defense of Free Speech Rest on a Mistake about Religion?”, Political Theory 40, pp. 318 ss. [citado sobre la versión publicada en ssrn (http://ssrn.com/abstract=1642754)].

Martínez Torrón, J. (2016). "Libertad de expresión y lenguaje ofensivo: algunos criterios prácticos de análisis jurídico”, El Cronista del Estado Social y Democrático de Derecho 60, p. 26 ss.

Martínez Torrón, J. (2015). "La tragedia de Charlie Hebdo: algunas claves para un análisis jurídico”, El Cronista del Estado Social y Democrático de Derecho 50, p. 22 ss.

Milanovic, M. (2018). "Legitimizing Blasphemy Laws Through the Backdoor: The European Court's Judgment in E.S. v. Austria”, en el blog EJIL: Talk!, 29 de oc- 
tubre de 2018. https://www.ejiltalk.org/legitimizing-blasphemy-laws-throughthe-backdoor-the-european-courts-judgment-in-e-s-v-austria/ (Última consulta: 21.05 .2021$)$.

Palomino, R. (2009). “Libertad religiosa y libertad de expresión, Ius Canonicum 98, pp. 509 ss.

Pérez-Madrid, F. (2009). “Incitación al odio religioso o 'hate speech' y libertad de expresión', Revista General de Derecho Canónico y Derecho Eclesiástico del Estado 19, pp. 1 ss.

Pinto, M. (2010). "What Are Offences to Feelings Really About? A New Regulative Principle for the Multicultural Era", Oxford Journal of Legal Studies 4, pp. 695 ss.

RAwls, J. (1996) Sobre las libertades, Barcelona, Paidós, $1^{a}$ reimpresión.

Roca Agapito, L. (2015). "Delitos contra la libertad de conciencia y los sentimientos religiosos”, en: Álvarez García (director), tratado de Derecho Penal. Parte Especial. IV. Delitos contra la Constitución, Valencia.

SMET, S. (2018). "E.S. v. Austria: Freedom of Expression versus Religious Feelings, the Sequel", en el blog: The Strasboug Observers, 7 de noviembre de 2018 (https://strasbourgobservers.com/category/cases/e-s-v-austria/). (Última consulta: 21.05 .2021$)$.

VÁzQuez Alonso, V. J. (2016). "Libertad de expresión y religión en la cultura liberal: de la moralidad cristiana al miedo postsecular", Boletín Mexicano de Derecho Comparado 146, pp. 306 ss.

Waldron, J. (2012). The Harm in Hate Speech, Harvard.

Weinsten, J. (2011) "Participatory Democracy as the Central Value of American Free Speech Doctrine”, Virginia Law Review 97, pp. 491 ss. 